\title{
COMERCIANTES E A GESTÃO DE RESÍDUOS SÓLIDOS: PERCEPÇÃO, VISIBILIDADE, RELEVÂNCIA E INCLUSÃO DE CATADORES DE MATERIAIS RECICLÁVEIS EM ARAÇUAÍ, MG
}

\author{
SILVA, Carlos Augusto Pereira da ${ }^{1}$ \\ SANTOS JÚNIOR, Valdevino José dos ${ }^{2}$ \\ LOPES, Manamares de Souza Coutinho ${ }^{3}$ \\ SANTOS, Eliane Macedo Sobrinho ${ }^{4}$ \\ OTONI, Bruna de Souza ${ }^{5}$
}

\begin{abstract}
Recebido em: 2020.05 .06
Aprovado em: 2020.09.15

ISSUE DOI: $10.3738 / 1982.2278 .3794$

RESUMO: Com a Política Nacional de Resíduos Sólidos (PNRS), emergiu a gestão de resíduos sólidos (GRS), tornando mais visível a presença dos catadores de materiais recicláveis na sociedade. Neste contexto, objetivou-se avaliar, no contexto da GRS, a percepção de comerciantes sobre os catadores de materiais recicláveis em Araçuaí, MG, bem como levantar aspectos sobre a visibilidade, relevância do trabalho e inclusão dos catadores na GRS do município. Para isto, aplicou-se 100 questionários com sete questões aos comerciantes de nove segmentos. Os resultados do estudo foram obtidos por meio das respostas de 62 dos 100 questionários aplicados aos comerciantes entrevistados, dos quais (82\%) funcionários, (13\%) gerentes e (5\%) proprietários, que, em sua maioria, demonstraram ter algum conhecimento acerca da GRS como coleta seletiva e materiais recicláveis, mas apresentaram baixa adesão à separação de resíduos. Quanto à visibilidade ao trabalho e à inclusão dos catadores na coleta de materiais recicláveis, verificou-se que os comerciantes dão importância ao trabalho desenvolvido pelos catadores, além de afirmar que destinariam os resíduos à uma associação municipal de catadores. Com relação aos catadores, o presente estudo levantou algumas questões socioeconômicas, mas estas devem ser aprofundadas para assim tornar ainda mais visível à relevância do trabalho dos catadores enquanto agentes ambientais. Dessa forma, é importante que o município de Araçuaí implemente um plano de GRS conforme a PNRS, devendo adotar a responsabilidade compartilhada, incentivar os comerciantes a separar materiais recicláveis com vistas à coleta seletiva e destiná-los à associação de catadores, propiciando trabalho formal, renda e benefícios ambientais .
\end{abstract}

Palavras-chave: Gerenciamento de Resíduos Sólidos. Catadores de Resíduos. Coleta Seletiva. Comércio. Associação de Catadores.

\section{TRADERS AND SOLID WASTE MANAGEMENT: PERCEPTION, VISIBILITY, RELEVANCE AND INCLUSION OF COLLECTORS OF RECYCLABLE MATERIALS}

SUMMARY: With the National Solid Waste Policy (NSWP), solid waste management (SWM) emerged, making the recyclable material collectors more visible in society. In this context, the objective was to evaluate, in the context of the SWM, the perception of traders about recyclable material collectors in Araçuaí, MG, as well as to raise aspects about the visibility, the relevance of the work and the inclusion of the collectors in the city. For this, a questionnaire with seven questions was applied to 62 traders in nine segments. The results showed that the majority of traders are composed of employees $(82 \%)$, managers $(13 \%)$ and owners $(5 \%)$, who demonstrated to have some knowledge about SWM as selective collection and materials recyclable, but showed low adherence to waste separation, a premise of selective collection. As for the visibility and the inclusion of waste pickers in the collection of recyclable

\footnotetext{
${ }^{1}$ ORCID iD- http://orcid.org/0000-0001-8949-3152 Engenheiro Ambiental, Faculdades Santo Agostinho, especialista em recursos hídricos e ambientais - UFMG, mestrando em engenharia ambiental - UFRJ. Docente de Engenharia Ambiental do Instituto Federal do Norte de Minas Gerais - Campus Araçuaí.

2 ORCID iD- http://orcid.org/0000-0001-6078-5282 Engenheiro ambiental, Faculdades Santo Agostinho, mestre em engenharia de biossistemas - UFF, doutorando em Programa de Pós-graduação Interdisciplinar em Meio Ambiente PPG-MA/UERJ.

${ }^{3}$ ORCID iD- http://orcid.org/0000-0002-4752-4501 Gestora ambiental pelo IFNMG - Campus Araçuaí.

${ }^{4}$ ORCID iD- http://orcid.org/0000-0002-1576-4957 Médica Veterinária - UFV, mestre em Ciências Agrárias UFMG, doutora em Ciências da Saúde - Unimontes. Docente do Instituto Federal do Norte de Minas Gerais Campus Araçuaí.

${ }^{5}$ ORCID iD- http://orcid.org/0000-0001-6522-4791 Engenheira Ambiental, Faculdades Santo Agostinho, especialista em Mineração e Meio Ambiente - UFRB. Secretária Municipal de Meio Ambiente de Araçuaí - MG.
} 
materials, it was found that traders attach importance to the work. In addition, the majority of them claimed that they would send the waste to an association of municipal waste pickers. Regarding the waste pickers, the present study raised some socioeconomic issues, but these must be deepened in order to make the relevance of the waste pickers work as environmental agents even more visible. We conclude that it is important for the municipality of Araçuaí to implement a SWM plan in accordance with the NSWP, which should adopt shared responsibility, encourage traders to separate recyclable materials for the purpose of selective collection and allocate them to the association of waste pickers, providing formal work, income and environmental benefits.

Keywords: Solid Waste Management. Waste Collectors. Selective Collection. Trade. Association of Waste Pickers.

\section{INTRODUÇÃO}

A geração e o destino dos resíduos sólidos urbanos (RSU) têm acarretado preocupações ambientais à sociedade neste século XXI (MARQUES et al., 2017). É alarmante a quantidade de produtos lançados pelo mercado, como também o volume de embalagens descartadas. A geração de tais resíduos, que posteriormente serão depositados em aterros sanitários ou em lugares impróprios, ocasiona impactos socioambientais e gera resultados danosos aos ecossistemas e ao homem. Esse fato pode ser visualizado tanto em grandes como pequenos municípios (GOUVEIA, 2012; OLIVEIRA et al., 2012; LOPES et al., 2019; SOLIANI et al., 2019).

A gestão de resíduos e o papel dos catadores como agentes ambientais ficaram em evidência nos últimos anos, após a Política Nacional de Resíduos Sólidos (PNRS), Lei 12.305, de agosto de 2010 (BRASIL, 2010). Com essa lei, a situação de uma classe de trabalhadores, os catadores de materiais recicláveis, até então excluída pela sociedade, tornou-se destaque (MOURA et al., 2016). Ademais, os catadores são tidos como notáveis prestadores de serviço ambiental à sociedade, uma vez que reduzem a quantidade de resíduos sólidos e seus decorrentes impactos nas cidades do Brasil. Boa parte dessas cidades tem menos de 20 mil habitantes e essas políticas pouco atingem ou reconhecem os catadores que vivem com diferentes situações de destinação final inadequada de resíduos sólidos (GONÇALVES et al., 2013).

O gerenciamento dos resíduos sólidos (GRS) engloba atividades que objetivam a redução de resíduos na origem, coleta seletiva e reciclagem, compostagem dos resíduos orgânicos, construção de aterros sanitários e outras maneiras de destinação final aos resíduos não recicláveis (BELTRAME; LHAMBY, 2013).

A organização de catadores de materiais recicláveis em associações ou cooperativas proporciona renda e emprego, ilustrando um novo meio de organização econômica para as esferas vulneráveis da população. Podendo gerar melhores condições de trabalho e reconhecimento 
social da profissão, que geralmente são realizados em ambientes com condições precárias, baseados em trabalho informal. Além disso, possibilita reivindicar direitos, ainda que no desempenho da função não estejam munidos de garantias trabalhistas, que lhes garantam direitos sociais (MOURA et al., 2016).

Conhecer a percepção da população acerca do GRS no local onde moram é importante, porque permite identificar o grau de informação da população sobre o assunto. Neste sentido, a percepção de comerciantes no contexto do GRS, sobre catadores de materiais recicláveis mostrase incipiente (LOPES et al., 2019), sendo fundamental, que esforços sejam feitos para preencher tal lacuna.

Diante deste quadro, o presente artigo tem como objetivo avaliar, no contexto do gerenciamento de resíduos sólidos, a percepção de comerciantes sobre os catadores de materiais recicláveis em Araçuaí, Minas Gerais, bem como levantar aspectos sobre a visibilidade, relevância do trabalho e inclusão dos catadores na gestão dos resíduos sólidos do município.

\section{METODOLOGIA}

\section{1 ÁREA DE ESTUDO}

Esta pesquisa foi realizada no município de Araçuaí, localizado na microrregião do Médio Jequitinhonha, Nordeste de Minas Gerais (Figura 1). O município possui uma extensão territorial de $2.236,279 \mathrm{~km}^{2}$ e sua população estimada em 2019, é de 36.708 habitantes. O município é considerado polo microrregional, em virtude dos vários serviços que oferece. Além disso, encontra-se no primeiro lugar do ranking da economia da microrregião (INSTITUTO BRASILEIRO DE GEOGRAFIA E ESTATÍSTICA - IBGE, 2020). 
Figura 1: Localização município de Araçuaí no estado de Minas Gerais.
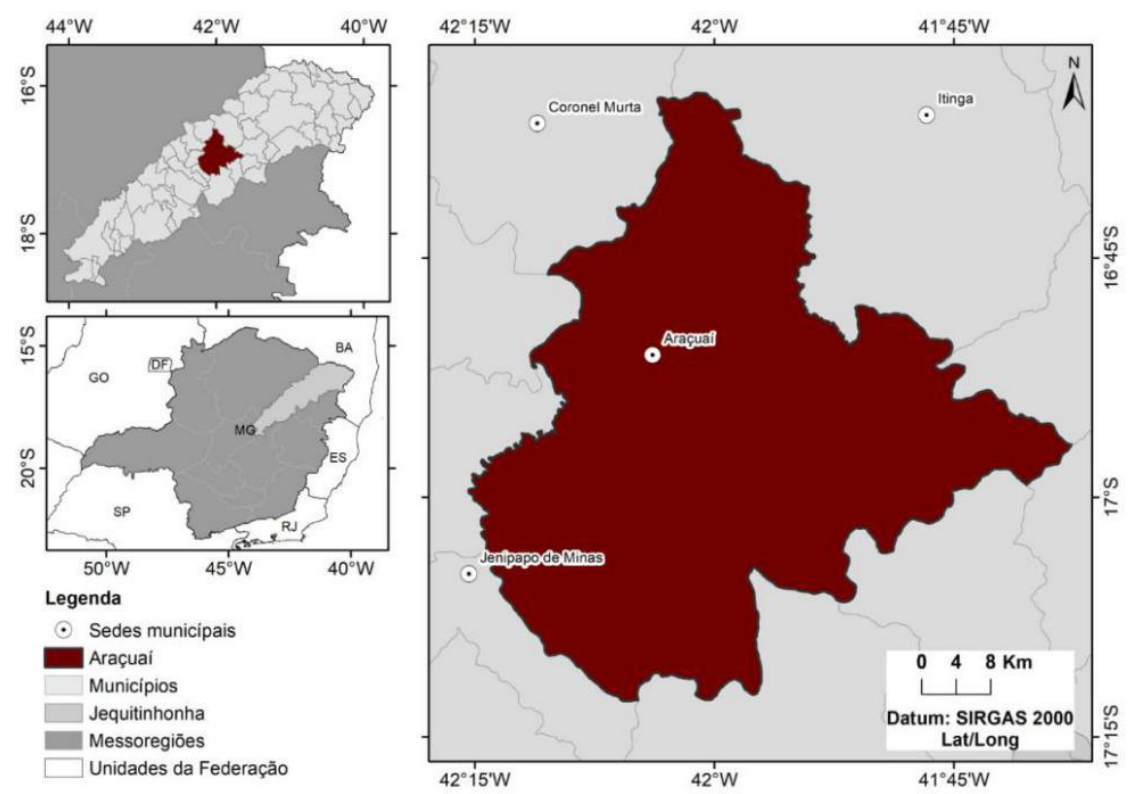

Fonte: Lopes et al. (2019).

\subsection{COLETA DOS DADOS}

O presente estudo tem uma abordagem metodológica descritiva com caráter exploratório. Nesse tipo de pesquisa, conseguem-se, na maior parte das vezes, descrições qualitativas e quantitativas do objeto de estudo, e o investigador deve conceituar as inter-relações entre as propriedades do fenômeno, fato ou ambiente observado (MARCONI; LAKATOS, 2010). O delineamento assumiu a forma de levantamento de dados direcionados ao grupo de interesse e em seguida, a apuração analítica dos dados (BELTRAME e LHAMBY, 2013).

Para a coleta de dados foi realizado primeiramente o levantamento do número de estabelecimentos comerciais próximos ao mercado municipal de Araçuaí, situado entre os bairros Centro e Alto Mercado, que foram convidados a participar da pesquisa. A partir disso foram aplicados 100 questionários estruturados aos proprietários, gerentes e colaboradores destes estabelecimentos, segundo os pressupostos teóricos de Gil (2014). Optou-se pela realização de uma amostragem por conveniência (não probabilística) de comerciantes. Para Oliveira et al. (2017) nesta amostragem, os elementos da amostra são selecionados por conveniência ou facilidade para o pesquisador.

Composto por sete perguntas (Quadro 1), o questionário teve por objetivo identificar os segmentos de comércio e obter a opinião dos comerciantes acerca da importância dos catadores 
de materiais recicláveis no gerenciamento de resíduos sólidos urbanos em Araçuaí/MG. Para assegurar a solidez e confiabilidade dos resultados, buscou-se escolher os participantes de forma abrangente, contemplando-se nove segmentos comerciais.

Quadro 1: Perguntas sobre o gerenciamento de resíduos sólidos e a importância do trabalho dos catadores de materiais recicláveis.

\begin{tabular}{|c|c|}
\hline 1 & Quem sou? \\
\hline & Proprietário ( ) \\
\hline 2 & Você sabe o que é coleta seletiva? \\
\hline & Não ( ) \\
\hline 3 & Você tem o hábito de separar o "lixo" no seu comércio? \\
\hline & Não ( ) \\
\hline 4 & Dentre estes itens, qual é o mais indicado para a reciclagem? \\
\hline & $\begin{array}{llll} & \text { Papelão, vidro e metais } & \text { Qualquer material de } & \\
\text { Produtos químicos ( ) } & (\text { ) } & \text { origem eletrônica ( ) }\end{array}$ Todos os itens ( ) \\
\hline 5 & Conhece algum(a) catador(a) ou associação de catadores? \\
\hline & Não ( ) \\
\hline 6 & Como você classifica o trabalho do catador de materiais recicláveis? \\
\hline & Muito importante ( ) $\quad$ Indiferente ( ) Nenhuma importância ( ) \\
\hline 7 & $\begin{array}{l}\text { Destinaria os resíduos recicláveis gerados em seu estabelecimento para um catador(a) ou } \\
\text { associação? }\end{array}$ \\
\hline & Não ( ) \\
\hline
\end{tabular}

A fim de auxiliar na implantação de programas de gerenciamento de resíduos sólidos, apresenta-se este estudo de caso como um instrumento, feito por meio de um trabalho de campo, com aplicação de questionários para o levantamento de informações, bem como à apresentação de um quadro das atuais condições da sociedade (OLIVEIRA et al., 2012).

A fim de facilitar as análises e discussão dos resultados, considerou-se como comerciantes todos os participantes, independentemente da função que desenvolvem nos estabelecimentos, haja vista, que as concepções sobre os temas abordados foram analisadas no âmbito das ações do comércio.

\section{RESULTADO E DISCUSSÃO}

Participaram do estudo, comerciantes de diferentes estabelecimentos distribuídos em nove segmentos, respondendo a 62 dos 100 questionários, sendo eles: lojas de confecção e calçados (10), lojas de confecção (10), lojas de variedades (10), farmácias (9), sapatarias (7), supermercados (6), papelarias (4), lojas de ferragens (4) e lojas de materiais de construção (2). 
De acordo com os resultados obtidos, $82 \%$ foram identificados como funcionários, $13 \%$ como gerentes e $5 \%$ como proprietários (Figura 2).

Figura 2: Identificação dos entrevistados.

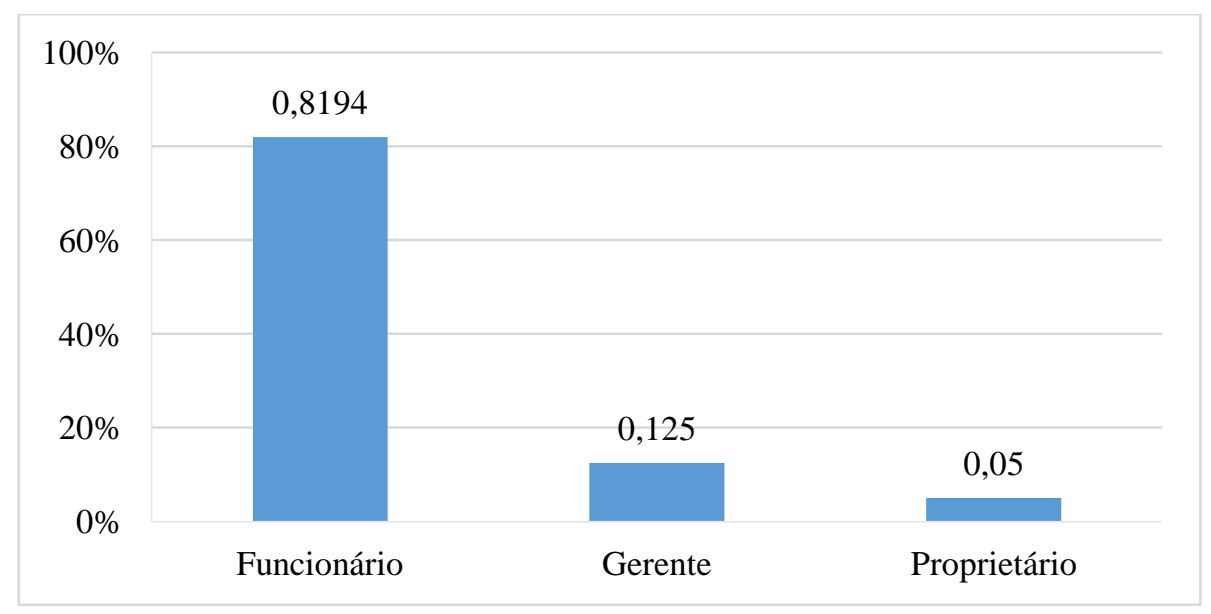

Fonte: Elaborado pelos autores

Os entrevistados foram questionados sobre o conhecimento do termo "coleta seletiva", e 95\% disseram saber do que se trata (Figura 3). Os percentuais mostraram que a maior parte dos participantes já ouviu falar do assunto, isso pode ser um reflexo de informações fornecidas por algum meio de comunicação realizado no município. Todavia, cabe salientar que mesmo os participantes tendo conhecimento do termo coleta seletiva, podem não ter ciência da relevância e necessidade proporcionada por sua implementação. Desta forma, analisar quais as práticas adotadas em relação à coleta seletiva que os comerciantes adotam nos seus estabelecimentos é necessária.

Figura 3: Percepção acerca do conhecimento do termo coleta seletiva.

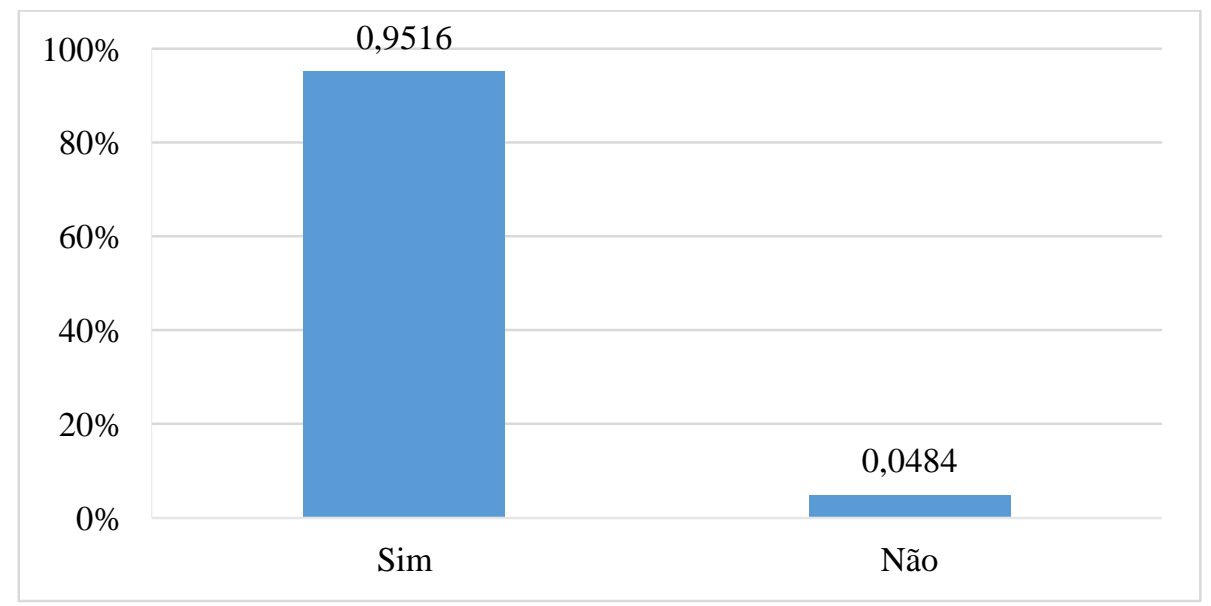

Fonte: Elaborado pelos autores 
Um exemplo da aplicação dos meios de comunicação para a disseminação de informações sobre a coleta seletiva, foi verificada em um consócio de municípios da região Noroeste do Rio Grande do Sul, RS, sendo utilizados, principalmente, panfletos, divulgação em rádio, escolas, comunicação porta-a-porta e em mídias sociais (GONÇALVES, 2019).

Bringhenti e Gunther (2011) em um estudo que avaliou a participação social em programas de coleta seletiva, em Vitória, Espírito Santo, afirmaram que a população conhece o termo coleta seletiva, e o associa a temática resíduos sólidos. Todavia, salientaram que a participação voluntária nestes programas ainda é pequena, mas tende a aumentar com sensibilização e mobilização social. Em outro estudo, que verificou a percepção dos moradores do município de Iomerê, Santa Catarina, grande parte dos participantes, 78\%, responderam saber o que é coleta seletiva. No entanto, o mesmo estudo apontou que a maioria dos moradores destinam os resíduos orgânicos juntamente ao lixo comum, 59\%, e, 71\%, também não sabem a diferença entre rejeito e resíduo (CAMPOS et al., 2017).

Sobre o hábito de separação de resíduos sólidos nos estabelecimentos comerciais, 69\% dos comerciantes responderam que não separam e 31\% afirmaram separar os resíduos, conforme o Figura 4. Verifica-se que apesar do alto nível de percepção em relação à questão anterior, observa-se uma incoerência quanto à prática da separação, dado que a maioria dos participantes responderam que não fazem separação. Nessa perspectiva, visualizam-se algumas circunstâncias. A primeira mostra o desconhecimento sobre os conceitos de separação e coleta seletiva, visto que são ações complementares, ou seja, primeiramente separam-se os resíduos sólidos por tipologia, para, em seguida, serem dispostos à coleta seletiva. Outra perspectiva, relaciona-se ao fato dos estabelecimentos não estarem adequados para a coleta seletiva.

Figura 4: Respostas sobre a separação de resíduos pelos comerciantes.

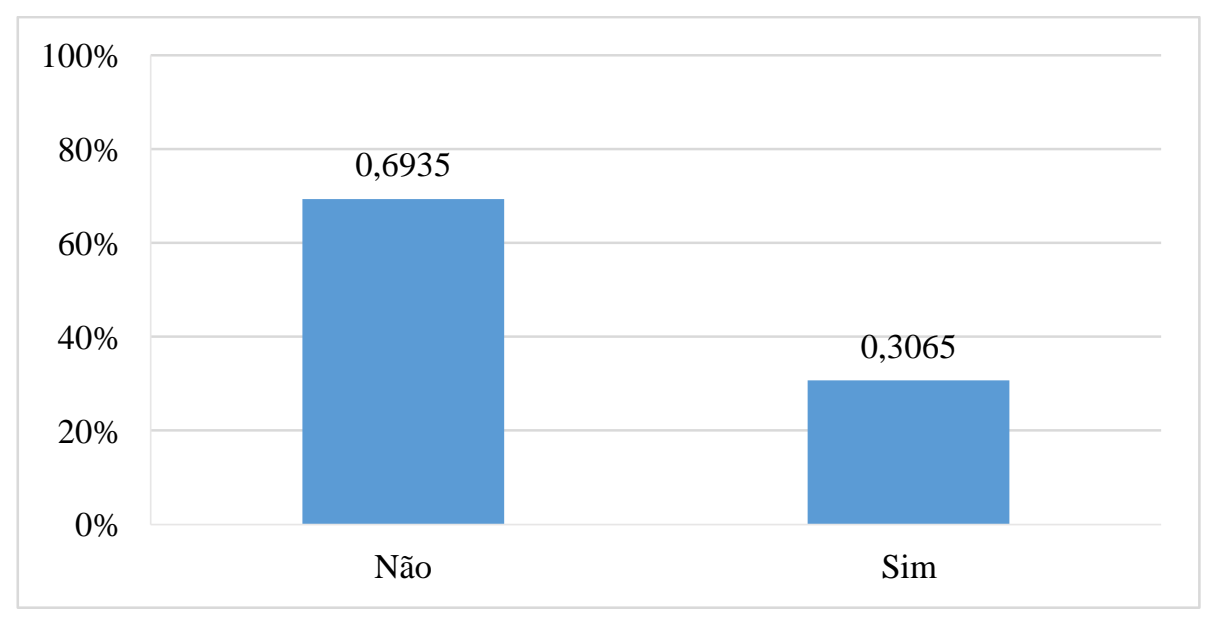

Fonte: Elaborado pelos autores 
O baixo engajamento dado à separação dos resíduos pelos comerciantes (31\%) pode estar associado à falta de uma política municipal de GRS ou que se tenha, pelo menos, alguma iniciativa para a coleta seletiva, e ainda, o desconhecimento da relevância do assunto sob os aspectos ambientais e até mesmo socioeconômico.

Sobre o conhecimento do conceito de coleta seletiva e à prática da separação, cenário semelhante foi constatado em um estudo desenvolvido por Rodrigues et al. (2016) no município de São Gabriel, RS, pois, observaram que a maioria da população de um bairro, $77 \%$, afirma ter conhecimento sobre coleta seletiva, mas apenas $40 \%$ pratica a separação.

Quanto à adequação dos estabelecimentos comerciais, a Resolução CONAMA nº 275/2001, recomenda a adoção do código de cores para programas de coleta seletiva implementados em órgãos públicos, iniciativa privada, organizações não-governamentais e outras instituições interessadas (BRASIL, 2001), além, de ser uma responsabilidade atribuída ao comércio, de acordo com a Política Nacional de Resíduos Sólidos (PNRS) (BRASIL, 2010).

A falta de conhecimento sobre a separação de resíduos foi uma das situações abordadas por gerentes, moradores e administradores das lojas de um conjunto residencial em Recife, PE, no qual, apenas $43 \%$ dos entrevistados separavam seus resíduos, e 57\% não faziam a separação (BELTRÃO et al., 2015). Em uma situação contrária a essa, Fujihara et al. (2017) verificaram que microempreendedores da cidade de Catanduvas, PR, fazem a separação dos resíduos passíveis de serem reciclados e os dispõe para a coleta frequentemente, denotando, assim, alguma percepção ambiental, seja em sua vida pessoal ou empresarial.

Diante desta situação, torna-se imprescindível que cada indivíduo como comerciante ou mesmo cidadão, participem de uma discussão que os conduza a uma reflexão sobre seus hábitos. Para isso uma análise de sua própria percepção sobre consumo, desperdício, o que são boas práticas ambientais, separação de resíduos e reciclagem, é necessária. Nesta direção ações de mobilização ambiental podem ser fundamentais para que bons resultados sejam alcançados.

Portanto, conclui-se que estas medidas devem obrigatoriamente estar incluídas em um plano de gestão de resíduos sólidos, cujo plano, deve ser implementado imediatamente pelo município, acompanhado de toda a infraestrutura que subsidie sua operacionalização. Através disso, a população de modo geral, adquirirá consciência para separação e coleta seletiva.

Indagados sobre a importância da reciclagem, 100\% dos comerciantes apontaram que esta é uma medida muito importante. Questionados também sobre quais os resíduos deveriam ser destinados à reciclagem, apenas uma pequena parcela dos entrevistados, 10\%, respondeu que 
todos os materiais devem ser reciclados (produtos químicos; papelão, vidro e metais; qualquer material de origem eletrônica) (Figura 5).

Figura 5: Percepção dos comerciantes sobre quais materiais devem ser reciclados.

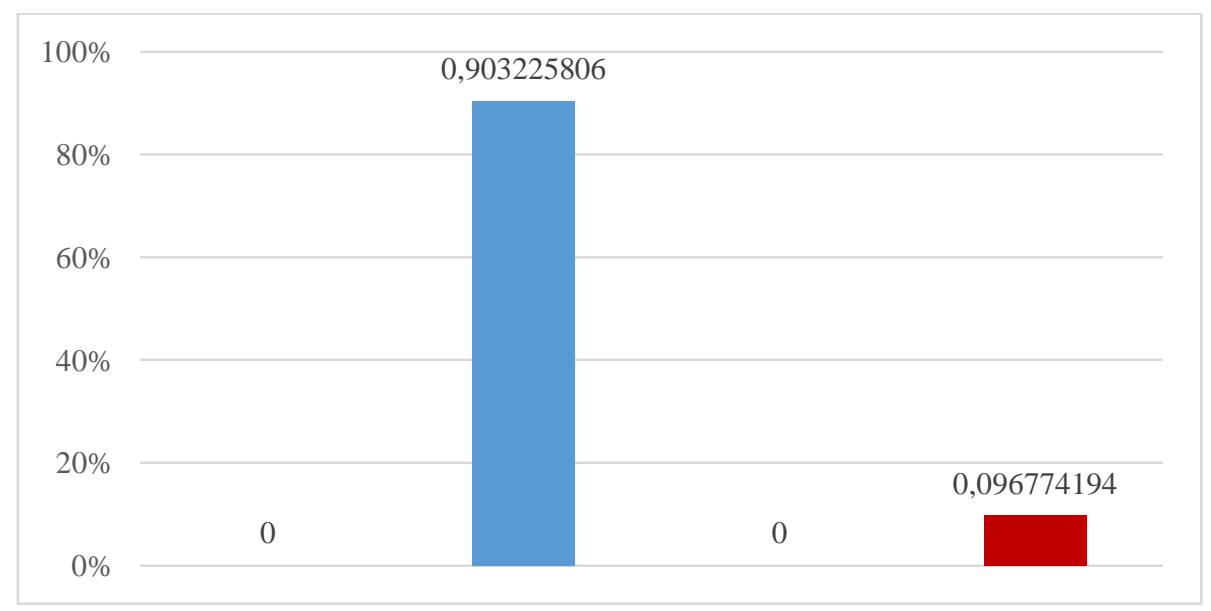

Fonte: Elaborado pelos autores

Apesar de a maioria não praticar a separação, conforme resultado da questão anterior, estes percentuais apontam que os entrevistados não encontrariam dificuldades para separarem e destinarem corretamente seus resíduos para um programa de coleta seletiva. Esse resultado pode refletir, como já discutido, a importância das informações mesmo que pontuais sobre o tema, visto que os materiais indicados nas respostas são produzidos em maior quantidade pela população em geral e, sempre estão associados a reciclagem e coleta seletiva.

Os resultados deste questionamento assemelham-se, também, aos da pesquisa realizada com moradores da zona urbana do município de São Sebastião da Lagoa, Paraíba, na qual 49\% afirmaram que os resíduos são materiais que não tem mais utilidade e que devem ser descartados, o que aponta para o desconhecimento sobre o reaproveitamento e a reciclagem dos resíduos sólidos (QUERINO; PEREIRA, 2016).

Bravo et al. (2018) analisando os conhecimentos de estudantes do município de Alegre/ES acerca dos resíduos sólidos, verificaram que 56\% dos entrevistados apontaram como materiais não recicláveis: papéis sanitários, fotos, filtros de cigarro; $30 \%$ as pilhas e baterias; $8 \%$ caixinha longa vida; $4 \%$ fotocópias, provas; e $2 \%$ revistas.

Em um trabalho que analisou a percepção de colaboradores de um Campus da Universidade Estadual da Paraíba sobre o GRS urbanos, os materiais papelão, garrafas plásticas, garrafas de bebidas foram classificados corretamente como recicláveis por $100 \%$ dos entrevistados. Apesar desse índice, $40 \%$ dos colaboradores também afirmaram que materiais como guardanapos, grampos, lenços de papel, papel vegetal e de fotografia, e 62,5\% apontaram o 
papel plastificado como recicláveis. No entanto, nenhum desses materiais pode ser destinado à reciclagem (SOARES et al., 2017).

A partir das análises feitas acerca da percepção dos comerciantes relativos aos temas inerentes à gestão dos resíduos sólidos, vislumbrou-se um cenário para que essa percepção fosse repensada, podendo ser construída por um importante sujeito inserido na sociedade: o catador de materiais recicláveis. Este importante ator social encontrado em diversas cidades brasileiras, desempenha dois papéis fundamentais, o de limpeza urbana e de iniciar o processo produtivo da reciclagem.

Diante dessa conjuntura, analisou-se também a percepção dos comerciantes sobre os catadores de materiais recicláveis. Assim, os entrevistados foram questionados se conhecem algum catador de materiais recicláveis ou associação no município (Figura 6).

Figura 6: Respostas sobre o conhecimento de algum catador (a) no município.

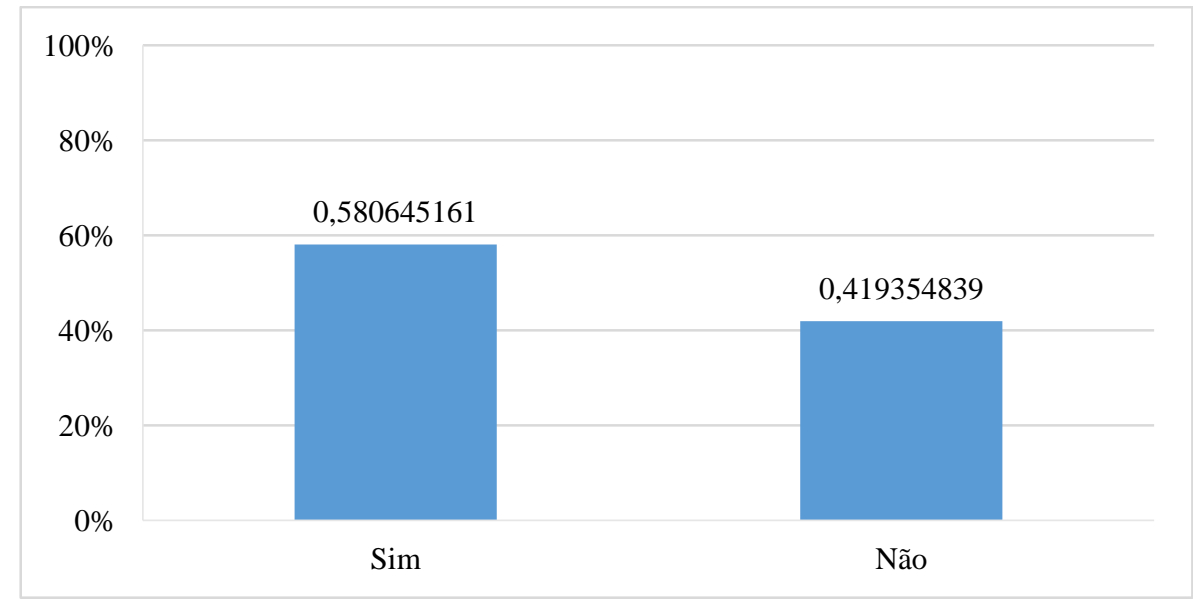

Fonte: Elaborado pelos autores

A maioria dos entrevistados, $58 \%$, responderam conhecer algum catador ou associação, e $42 \%$ disseram não conhecer.

É importante destacar que, em 2016, iniciou-se em Araçuaí, o município deste estudo, a inclusão de catadoras no programa de coleta seletiva municipal de resíduos sólidos, como forma de organização do trabalho de catadoras e catadores no município. Em dezembro de 2017, foi realizada uma panfletagem no bairro Centro, com a participação de catadoras. Os comerciantes foram abordados pelas catadoras, objetivando conscientizá-los quanto aos materiais passíveis de recicláveis, informá-los sobre o trabalho dos catadores e estabelecer parcerias para a coleta dos materiais recicláveis de seus comércios, Figuras 7A e 7B (PREFEITURA MUNICIPAL DE ARAÇUAÍ, 2016). Nessa perspectiva, em 2018, foi consolidada a RECRIAR (Associação das 
Catadoras e Catadores de Materiais Recicláveis de Araçuaí), com o apoio das Secretarias Municipais de Meio Ambiente e Desenvolvimento Social, integrantes do programa de coleta seletiva no município.

Figura 7 (A e B): Catadoras divulgando a associação RECRIAR.
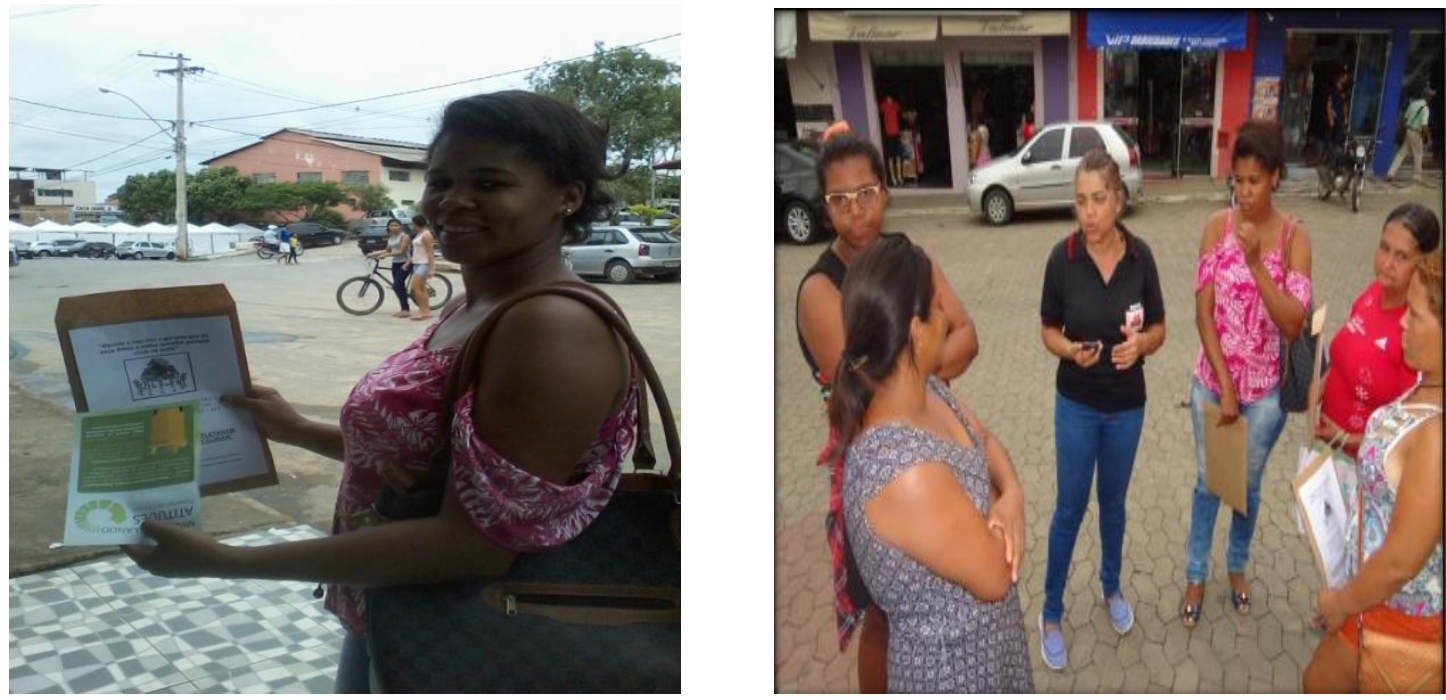

Fonte: Prefeitura Municipal de Araçuaí (2017).

Sobre a visibilidade dos catadores(as), o que se imagina na maioria das cidades brasileiras e, em Araçuaí não poderia ser diferente, é que os catadores de materiais recicláveis sejam (re)conhecidos pelo trabalho que fazem de recolher os resíduos sólidos recicláveis nos logradouros públicos. Também são conhecidos, por buscarem no lixo de moradores e comerciantes algum material que possa ser coletado e posteriormente comercializado para a reciclagem.

Analisando a visibilidade dos catadores, associações e cooperativas pela sociedade, o estudo de Guimarães; Rocha (2015), mostrou que a maioria dos moradores, 81\%, de um bairro da cidade Ituiutaba, MG, conhece a cooperativa, COOPERCICLA, por saber que ela está localizada no mesmo bairro, pela circulação dos caminhões pelas ruas e pela separação de resíduos para a cooperativa.

Há duas categorias de catadores, aqueles organizados ou não em associações ou cooperativas. Aqueles que não estão organizados em cooperativas ou associações, geralmente realizam o trabalho sem uniforme e utilizam veículos de tração manual, como os carrinhos de mão, ou de tração animal, como carroças. Por outro lado, os catadores organizados em cooperativas ou associações, dependendo de como essas instituições se encontram sob o aspecto financeiro, podem transmitir uma ideia de padronização do trabalho, com cooperados e associados trabalhando uniformizados e com melhor estrutura física para o trabalho. 
Vale salientar que "conhecer" algum catador ou associação, vai além das peculiaridades alusivas à forma de trabalhar ou dos equipamentos utilizados, envolve também a compreensão de sua condição social e econômica, que possibilite analisar o porquê da existência destes indivíduos.

Ressalta-se que não é objeto do presente estudo aprofundar na discussão dos aspectos históricos e organizacionais, bem como do perfil socioeconômico destes trabalhadores. Entretanto, de maneira genérica, vale salientar que este tipo de trabalho, no Brasil, segundo estudiosos, está relacionado ao aumento do desemprego e da precarização do trabalho na década 1990. Há estudos ainda, que mostram o surgimento de catadores de materiais recicláveis a partir da década de 1980.

Somando-se a isso, tem-se o perfil socioeconômico dos catadores, considerando a faixa etária, na qual geralmente predominam os mais idosos e o baixo nível de escolaridade. A prevalência de catadores mais idosos pode estar relacionada à perda do emprego em idade mais avançada ou como forma para complementar a renda da aposentadoria. O baixo nível de escolaridade também dificulta ou torna impossível a concorrência por uma vaga no mercado de trabalho formal, podendo atingir, inclusive, faixas etárias menos avançadas.

De acordo com o Movimento Nacional dos Catadores de Materiais Recicláveis (MNCR), existem aproximadamente 800 mil catadores(as) em atividade no país. Este número é resultado do crescimento de trabalhadores no segmento no Brasil, que passou de 150 mil para 500 mil, entre os anos de 1999 e 2004. Estudos sobre as iniciativas de associativismo e cooperativismo, destacam também, que a atividade de coleta de materiais recicláveis inclui a população de rua. Neste sentido, Escorel (2000) descreve que a catação de materiais recicláveis consiste numa atividade complementar, que entre as décadas 1980 e 1990, era desenvolvida pela população de rua (BORTOLI, 2013).

Discutindo o perfil socioeconômico destes trabalhadores, Bursztyn (2000) mostra que níveis de escolaridade mais baixos, intensa rotatividade, segmentarização dos vínculos e o trabalho precário, são característicos dessa atividade. Traçando o perfil socioeconômico dos catadores organizados em duas cooperativas na cidade de Natal, RN, Braz et al. (2014) descreveram que a maioria dos trabalhadores, $72,9 \%$, têm o ensino fundamental incompleto. No município de Fortaleza, CE, catadores de 11 associações pesquisadas, têm um baixo grau de escolaridade, das quais $21 \%$ são analfabetos e, $44 \%$ não concluíram o ensino fundamental (RODRIGUES et al., 2013). Essas situações de baixo nível de escolaridade, conforme Medeiros e 
Macedo (2006) constituem como fatores exclusão dos catadores no mercado de trabalho formal, que acaba conduzindo-os para a atividade de catador.

Em uma pesquisa que analisou o perfil socioeconômico dos catadores da Região Metropolitana de Porto Alegre, RS, foi observado que a maioria desses trabalhadores estão na faixa etária acima dos 50 anos (SCHWENGBER et al., 2016). Da mesma forma, Bosi (2008) discutindo sobre às diversas situações de trabalho dos catadores do Extremo Oeste do Paraná, verificou que $70 \%$ dos catadores encontravam-se na faixa etária entre 31 e 60 anos, e dos 41 aos 60 anos (faixa de idade mais avançada) totalizavam 70\% dos catadores.

No âmbito do desenvolvimento do trabalho, geralmente são utilizados como instrumento dos catadores, carrinhos de diversos tipos e modelos ou sacos apoiados nas costas, sem considerar os padrões ergonômicos, que podem ocasionar problemas decorrentes da má postura (RIBEIRO et al., 2015). Nesse viés, Cockell et al., (2004), a partir da análise ergonômica do trabalho na triagem de materiais recicláveis, apontou que os trabalhadores estão expostos a riscos de acidentes (cortes na mão) e doenças (transtornos respiratórios e alergias), bem como sofrimento psíquico, sobrecarga física e mental. Ademais, Cavalcante e Franco (2007) destacam que "o ato contínuo de curvar o corpo para apanhar os resíduos recicláveis ou carregar peso excessivo durante as coletas, triagem e acondicionamento".

Uma outra questão a ser discutida, refere-se à análise da importância do trabalho realizado pelos catadores de materiais recicláveis, em que praticamente todos os participantes, 98\%, disseram ser muito importante (Figura 8). Essa avaliação conduz a uma ideia de que os comerciantes tenham alguma percepção sobre o trabalho dos catadores, tendo como premissa a condição social e econômica de cada um. Podem analisar ainda como reflexo do trabalho de agente ambiental da coleta seletiva e reciclagem, haja vista que são os responsáveis por iniciarem o processo produtivo da reciclagem.

Sobre esses aspectos, o Guimarães e Rocha (2015) avaliam que o programa coleta seletiva desenvolvido no município de Ituiutaba, MG, contribui para a sustentabilidade ambiental e ainda gera renda para os cooperados da COOPERCICLA. 
Figura 8: Percepção dos comerciantes sobre a importância do trabalho dos catadores.

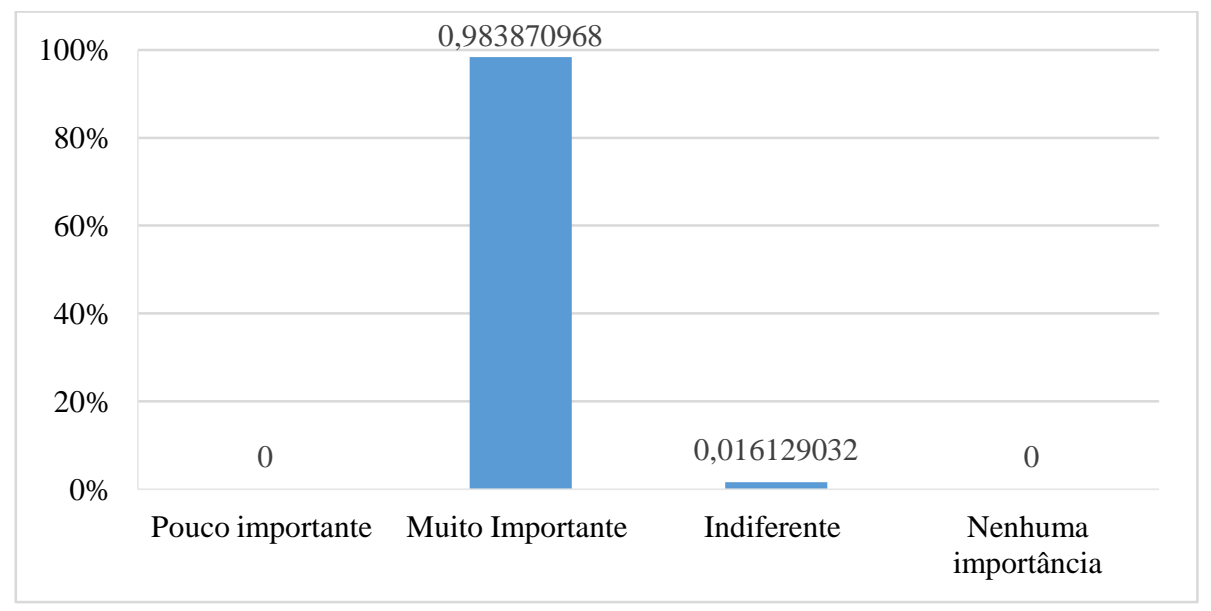

Fonte: Elaborado pelo autor

No que diz respeito à importância do trabalho dos catadores, associações e cooperativas de materiais recicláveis, estudos demonstram sua relevância. Fazendo uma abordagem da relação entre o poder público municipal e a participação dos catadores, Romani (2004) expõe que a valorização e importância do catador deve ser o resultado do papel fundamental que ele exerce na reintrodução de matéria-prima secundária na cadeia de produção e consumo, quando de sua organização. Com a aprovação da PNRS, as cooperativas e associações de catadores possibilitam os fluxos reversos de materiais recicláveis, uma vez que são latentes provedoras desses materiais às empresas (DEMAJOROVIC et al., 2014).

Avaliando a percepção da importância do trabalho de catação sob o olhar do catador, a maioria dos catadores de associações e cooperativas da Região Metropolitana de Recife, afirmam que o seu trabalho é importante para as pessoas, especialmente, por manterem a cidade limpa. Apesar disso, ainda tem pessoas que os discriminam (ROLIM et al., 2015). Em um estudo de caso sobre gestão dos resíduos sólidos e a educação ambiental feito no município de Lavras, MG, Bicalho et al. (2016) verificaram que 55,3\% e 34,7\% da população investigada, avaliaram como muito importante e importante, respectivamente, a participação do catador na gestão dos resíduos sólidos.

Com base nesta conjuntura analisada e discutida que possibilitou identificar as percepções dos comerciantes do município e sua participação na GRS urbanos, bem como a importância dos catadores, foram questionados também como isto se daria. Neste sentido, foram indagados se estariam dispostos a destinar seus resíduos para a associação (Figura 9).

Nucleus, v.17, n.2, out. 2020 
Figura 9: Percepção dos comerciantes sobre a destinação dos resíduos sólidos recicláveis para associação.

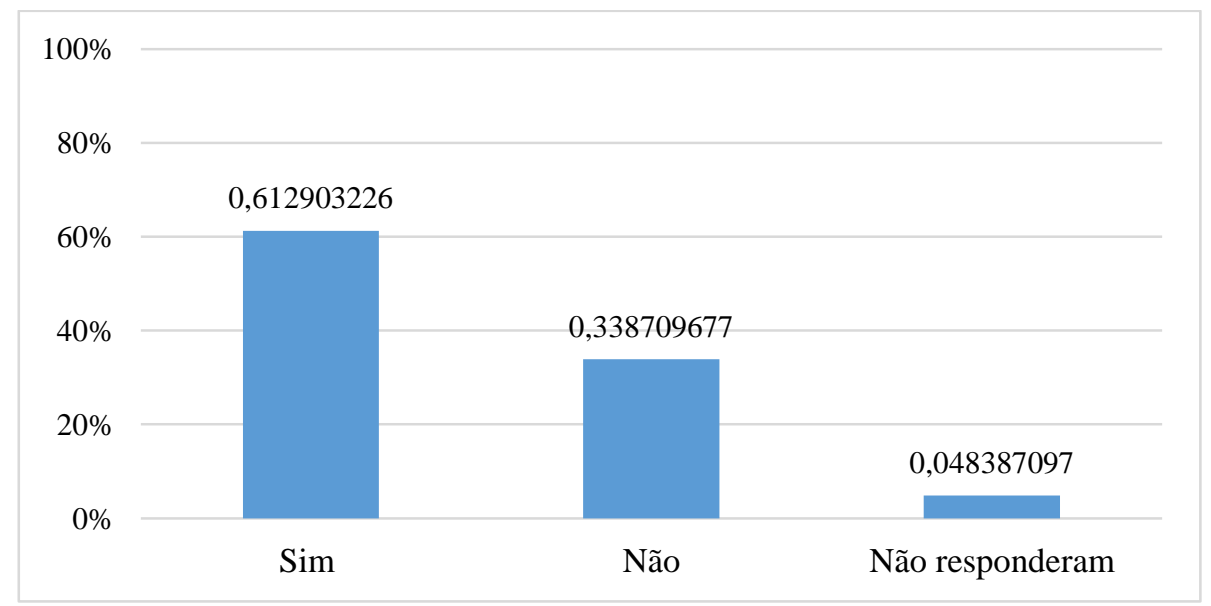

Fonte: Elaborado pelo autor

Entre as repostas obtidas, 61\% disseram que destinariam à associação, o que representa um percentual satisfatório, embora não coincida com a importância dada ao trabalho dos catadores, como observado na questão anterior. Quanto aos demais entrevistados, $34 \%$ afirmaram que não disporiam seus resíduos para a associação, e 5\%, não responderam.

Com esses resultados, pode-se inferir que grande parte dos comerciantes tem uma percepção concreta da importância do trabalho dos catadores, sobretudo, do ponto de vista social e econômico, conforme discutido na questão anterior. Porém, verifica-se que nem todos têm essa percepção, mesmo que praticamente todos tenham considerado o trabalho de catação importante.

Esse cenário aponta para a necessidade de um trabalho de sensibilização dos comerciantes, através de temas que relacionem às questões socioeconômicas e à problemática dos resíduos sólidos, ao trabalho do catador. Acerca da sensibilização para a coleta de resíduos sólidos pelos catadores, Silva et al., (2013) observaram que uma associação de catadores do município de São Manuel, SP, passou a receber mais resíduos da população devido ao trabalho de sensibilização, abordando o problema dos resíduos sólidos mediante palestras, folders e da educação ambiental com propagandas planejadas nos três níveis de ensino municipal e particular.

Além destes aspectos, deve-se estimular a destinação de resíduos aos catadores, abordando-se a responsabilidade compartilhada, prevista como um dos instrumentos da PNRS. Essa lei define que os diversos segmentos, incluindo o comércio, são responsáveis pelos seus resíduos, e podem "atuar em parceria com cooperativas ou outras formas de associação de catadores de materiais reutilizáveis e recicláveis" (BRASIL, 2010).

Com base nisso, a coleta de resíduos sólidos de segmentos da sociedade e do setor empresarial por associações e cooperativas de catadores, tem sido contextualizada em vários 
estudos com uma abordagem alusiva à responsabilidade compartilhada, logística reversa e também sustentável.

Neste contexto, em um estudo de caso feito no município de Palmas, TO, foi possível perceber que uma associação e uma cooperativa de catadores de materiais recicláveis são responsáveis por coletar resíduos em órgãos públicos, empresas privadas, condomínios; tendo uma importante atuação na logística reversa em Palmas. Além de contribuir para conservação ambiental, geração de empregos, renda e inclusão social de pessoas em situação de vulnerabilidade (BARRETO et al., 2015).

Em outro estudo semelhante, Almeida et al. (2013) verificaram que seis cooperativas do município de São Leopoldo, RS, recebem resíduos de aproximadamente 90 empresas comerciais e industriais. Demajorovic et al. (2014) analisaram a construção de fluxos reversos entre três empresas e a Cooperativa Vira-Lata, em São Paulo, e observaram que ambos obtiveram benefícios ambientais, sociais e econômicos.

Toda esta conjuntura, mostra que a administração pública municipal deve analisar a relevância de se implementar de um Plano de Gerenciamento de Resíduos Sólidos Urbanos, no qual, a responsabilidade compartilhada como um de seus instrumentos, seja impulsionada nos moldes definidos na PNRS e, que possibilite a construção de uma integração entre os comerciantes e a RECRIAR com vistas à coleta dos resíduos recicláveis.

Diante disso, vislumbram-se ganhos na dimensão ambiental, principalmente, quanto à coleta de resíduos, que atualmente são dispostos em um aterro municipal controlado, e na dimensão social e econômica, que mediante a coleta realizada pela associação, os catadores poderão ter um trabalho formal e ainda acesso à renda.

\section{CONSIDERAÇÕES FINAIS}

O presente estudo que teve como objetivo avaliar a percepção de comerciantes sobre catadores de materiais recicláveis em Araçuaí, MG, no contexto da gestão de resíduos sólidos, apontou que praticamente todos os comerciantes mostram ter conhecimento sobre assuntos mais pontuais relativos à gestão dos resíduos sólidos, como coleta seletiva e os tipos de resíduos que são passíveis de serem reciclados. No entanto, em relação à separação destes resíduos, apenas uma pequena parcela afirmou desenvolver esta prática.

Com relação aos catadores, sob os aspectos da visibilidade, importância do trabalho e participação na coleta dos resíduos sólidos recicláveis, o estudo também demonstrou, 
principalmente, que os comerciantes avaliam como importante o trabalho do catador, embora, uma pequena parcela ainda não observe desta forma, haja vista que não destinariam os resíduos à associação RECRIAR.

Essas circunstâncias tornam fundamental a realização de um trabalho de sensibilização dos comerciantes, que os possibilite uma melhor compreensão destes temas, especialmente, a respeito da separação dos resíduos recicláveis. Neste trabalho é importante ainda, que os assuntos relacionados aos catadores, especialmente, acerca das questões sociais e econômicas também sejam aprofundados, para assim, tornar ainda mais visível a relevância do trabalho dos catadores que já desenvolvem um importante papel de agente ambiental.

Diante de toda essa conjuntura, observa-se, ainda, que é fundamental a implementação pela administração pública do município de um plano municipal de gerenciamento de resíduos sólidos segundo os moldes da PNRS. Neste sentido, o desenvolvimento da responsabilidade compartilhada como um dos componentes destes moldes será fundamental, haja vista, que consiste em um instrumento cuja execução deve ser incentivada. Com isso, a separação dos resíduos passíveis de serem reciclados com vistas à coleta seletiva será estimulada e, ainda possibilitará a integração dos catadores e catadoras da RECRIAR, permitindo-lhes o acesso a um trabalho formal, a uma fonte de renda, além de benefícios ambientais ao município.

Por fim, recomenda-se o desenvolvimento de estudos semelhantes a este, pois, não há na literatura, trabalhos que façam uma abordagem da percepção do setor comercial sobre os temas apresentados, e as pesquisas encontradas que se propõem a discutir tais temas restringem-se às grandes empresas.

\section{REFERÊNCIAS}

ALMEIDA, F.; VIANA, A.; RITTER, A.; SELLITTO, M. Cooperativas de catadores de resíduos e cadeias logísticas reversas: estudo de dois casos. REGET, Santa Maria, v. 17, n. 2, p. 33763387, 2013. DOI: http://dx.doi.org/10.5902/2236117010911

BARRETO, O. A. C.; SILVA, J. M. dos S.; GORI, R. S. L.; SELLITTO, M. A. Logística reversa como ferramenta para sustentabilidade: um estudo sobre cooperativas de catadores de resíduos no Tocantins. REGET, Santa Maria, v. 19, n. 2, p. 332-343, 2015. DOI:

http://dx.doi.org/10.5902/2236117016094

BELTRAME, T. F.; LHAMBY, A. Coleta seletiva: percepção e conhecimento sobre o tema uma pesquisa exploratória. REMOA, Santa Maria, v. 12, n. 12, 2013. DOI:

http://dx.doi.org/10.5902/223613088323

BELTRÃO, M. R. M.; DUTRA, M. T. D.; NUNES, A. T. Percepção ambiental sobre a gestão de resíduos sólidos: estudo de caso do conjunto residencial Pernambuco. Revista Gestão \&

Sustentabilidade Ambiental, Florianópolis, v. 4, n. 2, p. 209-233, 2015. DOI:

http://dx.doi.org/10.19177/rgsa.v4e22015209-233

Nucleus, v.17, n.2, out. 2020 
BICALHO, M. L.; PEREIRA, J. R.; LAUDARES, S. S. de A. Gestão dos resíduos sólidos e a educação ambiental: um estudo de caso de Lavras, Minas Gerais. Revista Ibero-Americana de Ciências Ambientais, Aracaju, v. 7, n. 1, p. 82-96, 2016. DOI: http://doi.org/10.6008/SPC2179$\underline{6858.2016 .001 .0007}$

BOSI, A. P. A organização capitalista do trabalho "informal": o caso dos catadores de recicláveis. Revista Brasileira de Ciências Socias, São Paulo, v. 23, n. 67. p. 101-116, 2008. DOI: http://dx.doi.org/10.1590/S0102-69092008000200008

BORTOLI, M. A. Processos de organização de catadores de materiais recicláveis: lutas e conformações. Revista Katálysis, Florianópolis, v. 16, n. 2, p. 248-257, 2013. DOI: https://doi.org/10.1590/S1414-49802013000200011

BRASIL. Lei no 12.305 de 2 de agosto de 2010. Institui a Política Nacional de Resíduos Sólidos, altera a Lei $\mathrm{n}^{\circ}$ 9.605, de 12 de fevereiro de 1998 e dá outras providências. Diário Oficial da República Federativa do Brasil, Brasília, DF, 2010.

BRAVO. T. L.; PEÇANHA, A. L.; WERNER, E. T.; SANTOS, A. A. O. Educação ambiental e percepção da implantação de coleta seletiva de lixo urbano em de Alegre, ES. Revista Gestão \& Sustentabilidade Ambiental, Florianópolis, v. 7, n. 1, p. 375-396, 2018. DOI: http://dx.doi.org/10.19177/rgsa.v7e12018375-396

BRAZ, R. de F. dos S.; BISPO, C. de S. B.; COLOMBO, C. R.; MEDEIROS, M. F. S.; SILVA, J. C. S.; TEIXEIRA, M. T. da C.; SARTHOUR, S. A.; SOUZA, M. de F. de. Estudo sobre os aspectos sócio-econômicos dos catadores de resíduos recicláveis organizados em cooperativas na cidade de Natal - RN. REMEA, Rio Grande, p. 147-159, 2014.

BRINGHENTI, J. R.; GUNTHER, W. M. R. Participação social em programas de coleta seletiva de resíduos sólidos urbanos. Engenharia Sanitária e Ambiental, Rio de Janeiro, v.16, n.4, p.421-430, 2011. DOI: https://doi.org/10.1590/S1413-41522011000400014

BURSZTYN, M. (Org). No meio da rua: nômades, excluídos e viradores. Rio de Janeiro: Garamond, 2000.

CAMPOS, R. F. F. de; BORGA, T.; SARTOREL, A. Percepção dos moradores sobre a implantação de um sistema de coleta seletiva no município de Iomerê, Santa Catarina, Brasil.

Revista Brasileira de Geografia Física, Recife, v. 10, n. 5, p. 15511-1519, 2017. DOI: https://doi.org/10.26848/rbgf.v10.5.p1511-1519

CAVALCANTE, S.; FRANCO, M. F. A. Profissão perigo: percepção de risco à saúde entre os catadores do Lixão do Jangurussu. Revista Mal-estar e Subjetividade, Fortaleza, v. 7, n. 1, p. 211-231, 2007.

COCKELL, F. F.; CARVALHO, A. M. C. de; CAMAROTTO, J. A.; BENTO, P. E. G. A triagem de lixo reciclável: análise ergonômica da atividade. Rev. bras. saúde ocup., São Paulo, v. 29, n. 110, p. 17-26, 2004. DOI: https://doi.org/10.1590/S0303-76572004000200003 
DEMAJOROVIC, J.; CAIRES, E. F.; GONÇALVES, L. N. S.; SILVA, M. J. C. Integrando empresas e cooperativas de catadores em fluxos reversos de resíduos sólidos pós-consumo: o caso Vira-Lata. Cad. EBAPE.BR, Rio de Janeiro, v. 12, n. 7, p. 513-532, 2014. DOI: https://doi.org/10.1590/1679-39519020

FUJIHARA, H. M. L.; BRANDALISE, L. T.; BERTOLINI, G. Análise da percepção ambiental dos microempreendedores da cidade de Catanduvas-PR. Revista Eletrônica do CRA-PR, v. 4, n. 1, p. 64-78, 2017.

GIL, A. C. Métodos e técnicas de pesquisa social. 6 ed. São Paulo: Atlas, 2014.

GONÇALVES, C. V.; MALAFAIA, G.; CATROS, A. L. S.; VEIGA, B. G. A. A vida no lixo: um estudo de caso sobre os catadores de materiais recicláveis no município de Ipameri, GO. HOLOS, Natal, v. 2, p. 238-250, 2013. DOI: https://doi.org/10.15628/holos.2013.841

GONÇALVES, D. B.; PINHEIRO, D. K. Perspectivas dos gestores ambientais dos municípios consorciados ao CIGRES no processo de implantação da coleta seletiva. REMOA, Santa Maria, v. 18, n. 10, p. 01-13, 2019. DOI: http://dx.doi.org/10.5902/2236130840176

GOUVEIA, N. Resíduos sólidos urbanos: impactos socioambientais e perspectiva de manejo sustentável com inclusão social. Ciência \& Saúde Coletiva, Rio de Janeiro, v. 17, n. 6, p. 15031510, 2012. DOI: http://dx.doi.org/10.1590/S1413-81232012000600014

ESCOREL, S. Vivendo de teimoso. In: BURSZTYN, M. (Org.). No meio da rua: nômades excluídos e viradores. Rio de Janeiro: Garamond, 2000, p. 179-171.

GUIMARÃES, R. R.; ROCHA, L. A Percepção dos moradores quanto à coleta Seletiva: um estudo de caso no bairro Progresso, Ituiutaba (MG). Boletim Gaúcho de Geografia, Porto Alegre, v. 42, n. 1, p. 319-336, 2015.

INSTITUTO BRASILEIRO DE GEOGRAFIA E ESTATÍSTICA - IBGE. Panorama. 2010. Disponível em: < https://cidades.ibge.gov.br/brasil/mg/aracuai/panorama >. Acesso em: 25 abr. 2020.

LOPES, M. S. C.; SILVA, C. A. P.; SANTOS, E. M. S.; SANTOS JÚNIOR, V. J. Percepção de comerciantes sobre o gerenciamento de resíduos sólidos urbanos em Araçuaí/MG. Natural Resources, v. 9, n. 3, p. 10-17, 2019. DOI: 10.6008/CBPC2237-9290.2019.003.0002

LOUREIRO, C. F. B. Educação ambiental crítica: contribuições e desafios. In: MELLO, S. S., TRAJBER, R. (Coord.). Vamos Cuidar do Brasil: conceitos e práticas em educação ambiental na escola. Brasília: Ministério da Educação/Ministério do Meio Ambiente/UNESCO, 2007.

MARCONI, M. A. de; LAKATOS, E. M. Fundamentos de metodologia cientifica. 7 ed. São Paulo: Atlas, 2010.

MARQUES, E. A. F.; VASCONCELOS, M. C. R. L.; GUIMARÃES, E. H. R.; BARBOSA, F. H. F. Gestão da coleta seletiva de resíduos sólidos no campus Pampulha da UFMG: desafios e impactos sociais. Revista de Gestão Ambiental \& Sustentabilidade, Florianópolis, v. 6, n. 3, 2017. 
MEDEIROS, L. F. R.; MACÊDO, K. B. Catador de material reciclável: Uma profíssão para além da sobrevivência? Psicologia \& Sociedade, Belo Horizonte, v. 18, n. 2, p. 63-71, 2006. DOI: https://doi.org/10.1590/S0102-71822006000200009

MOURA, G. R. de; SERRANO, A. L. M.; GUARNIERI, P. Análise socioeconômica dos catadores de lixo no Distrito Federal. HOLOS, Natal, v. 3, p. 251-273, 2016. DOI: https://doi.org/10.15628/holos.2016.1857

OLIVEIRA, E. da S.; ALVES, C. E.; DOUHI, N. A percepção dos moradores sobre coleta seletiva na comunidade de Terra Nova do Piquiri, município de Assis Chateaubriand-PR. Revista Uniabeu, [S.1.], v. 5, n. 9, 2012.

OLIVEIRA, M. O. R.; LUCE, F. B.; SAMPAIO, C. H.; PERIN, M. G.; SANTINI, F. O.; SANTOS, M. F. Análise da qualidade dos artigos científicos da área de Marketing publicados no Brasil: as pesquisas survey na década de 2000. REAd. Rev. eletrôn. adm., Porto Alegre, v.23, n.1, 2017. DOI: https://doi.org/10.1590/1413-2311.024.55683

PREFEITURA MUNICIPAL DE ARAÇUAÍ. Organização da coleta seletiva solidária em Araçuaí/MG. Disponível em: <http://abm.org.br/ods/wpcontent/uploads/observatorio/676bd920c59b78c1b60452fbc1be3e10.pdf >. Acesso em: 22 abr. 2020 .

QUERINO, L. A. L.; PEREIRA, J. P. G. Geração de resíduos sólidos: a percepção da população de São Sebastião de Lagoa de Roça, Paraíba. REMOA, Santa Maria, v. 15, n. 1, p. 404-415, 2016. DOI: https://doi.org/10.5902/2236130819452

RIBEIRO, L. A.; SILVA, M. P. S. Tecnologia social para coleta e transporte de resíduos sólidos: Uma contribuição ao exercício profissional de catadores de materiais recicláveis. Polêmica, Rio de Janeiro, v. 15, n. 3, p. 2015. DOI: 10.12957/polemica.2015.19354

RODRIGUES, A. M.; SANTOS, N. R. Z. dos; GRACIOLI, R. C. Avaliação da percepção da população gabrielense e de algumas instituições do município quanto ao cumprimento da Política Nacional dos Resíduos Sólidos. Ciência e Natura, Santa Maria, v. 38, n. 2, p. 873 - 888, 2016. DOI: http://dx.doi.org/10.5902/2179460X21886

RODRIGUES, R. H. P.; ALMEIDA, P. C. de. A Contribuição das Associações na Inclusão Produtiva e Social dos Catadores de Materiais Recicláveis do Município de Fortaleza. Conhecer: Debate entre o Público e o Privado, Fortaleza, v. 3, n. 7, p. 155-202, 2013.

ROLIM, R. S.; TEIXERIA, K. M. D.; FERNANDES, R. A. U. "Uns valorizam, outros discriminam": família e sociedade na percepção dos catadores de materiais recicláveis. Oikos: Revista Brasileira de Economia Doméstica, Viçosa, v. 26, n. 1, p. 205-224, 2015.

ROMANI, A. P. O poder público municipal e as organizações de catadores. IBAM/DUMA/CAIXA, 2004.

SCHWENGBER, D.; SOUZA, A. de; CARDOSO, J. da C.; BIZANI, D. Perfil socioeconômico de profissionais catadores de quatro cooperativas de resíduos sólidos da região metropolitana de 
Porto Alegre/RS, Brasil. Revista Saúde e Desenvolvimento Humano, Canoas, v. 4, n. 2, 2016. DOI: http://dx.doi.org/10.18316/2317-8582.16.33

SOARES, J. A. S.; PEREIRA, S. S.; CÂNDIDO, G. A. Gestão de resíduos sólidos e percepção ambiental: um estudo com colaboradores do campus I da Universidade Estadual da Paraíba. RESMA, Três Lagoas, v. 4, n. 1, p. 39-54, 2017.

SOLIANI, R. D.; KUMSCHLIES, M. C. G.; SCHALCH, V. A gestão de resíduos sólidos urbanos como estratégia de sustentabilidade. Revista Espacios, Caracas, v. 40, n. 3, 2019. 